\title{
Lipoprotein(a) as an Independent Risk Factor for Diabetic Retinopathy in Male Patients in Non-Insulin-Dependent Diabetes Mellitus
}

\author{
Tomio Onuma, Toru Kikuchi, Michitaka Shimura, \\ Masahiro Tsutsui, Jun Matsui, Akitoshi Boku and \\ KazUo TAKeBE
}

\author{
The Third Department of Internal Medicine, Hirosaki \\ University School of Medicine, Hirosaki 036
}

\begin{abstract}
Onuma, T., Kikuchi, T., Shimura, M., Tsutsui, M., Matsui, J., Boku, A. and TAKEBE, K. Lipoprotein(a) as an Independent Risk Factor for Diabetic Retinopathy in Male Patients in Non-Insulin-Dependent Diabetes Mellitus. Tohoku J. Exp. Med., 1994, 173 (2), 209-216 — Relationship of the lipoprotein(a) $[\mathrm{Lp}(\mathrm{a})]$ concentration as a risk factor independent of other factors with the severity of diabetic retinopathy were evaluated by multiple regression analysis. The subjects were 158 patients with non-insulin-dependent diabetes mellitus (NIDDM). Multiple regression analysis was carried with the severity of diabetic retinopathy as the dependent variable and 13 independent variables, namely the $\mathrm{Lp}$ (a) concentration, sex, age, body mass index, duration of diabetes, ischemic heart disease, fasting plasma glucose, glycosylated hemoglobin Alc, total cholesterol, triglyceride, high-density lipoprotein cholesterol, anti-diabetic treatments, and diabetic nephropathy. The analysis was performed separately in all subjects, males only, and females only. The standard partial regression coefficient of $\mathrm{Lp}(\mathrm{a})$ was significant $(0.293, p<0.01)$, and the multiple correlation coefficient was 0.611 in the males. However, the standard partial correlation coefficient of $L p(a)$ was not significant in all patients and in females only. The rank of contribution of $\mathrm{Lp}$ (a) to retinopathy was the third in males, following triglyceride and nephropath$y$ and followed by anti-diabetic treatments. These results suggest that $\mathrm{Lp}(\mathrm{a})$ might be an independent risk factor for diabetic retinopathy in male patients with NIDDM. — lipoprotein(a); diabetic retinopathy; NIDDM; multiple regression analysis
\end{abstract}

Lipoprotein(a) $[\mathrm{Lp}(\mathrm{a})]$, which resembles low-density lipoprotein (LDL) (Fless et al. 1986), was first reported by Berg in 1963. Subsequent studies suggested that $\mathrm{Lp}(\mathrm{a})$ is associated with atherosclerosis, and Rosengren et al. (1990) reported that $L p(a)$ is an independent risk factor for coronary atherosclerosis. The serum $\operatorname{Lp}(a)$ was recently found to be increased in diabetic patients at various institutions (Arauz 1990; Takegoshi et al. 1990), but the mechanism of this

Received December 28, 1993; revision accepted for publication April 5, 1994.

Address for reprints: T. Onuma, The Third Department of Internal Medicine, Hirosaki University School of Medicine, 5 Zaifu-cho, Hirosaki 036, Japan. 
increase has not been clarified. An association between diabetic nephropathy and high $\mathrm{Lp}$ (a) levels was suggested by recent reports, attracting attention to the relationship between diabetic microvascular complications and $L p(a)$. There have also been a few reports on an association between diabetic retinopathy and high Lp(a) levels (Kohner and Porta 1990; Jenkins et al. 1991; Maioli et al. 1993). However, it remains unknown if diabetic retinopathy is related to $\operatorname{Lp}(a)$ independent of other risk factors. Diabetic retinopathy is considered to occur frequently in diabetic patients with poorly controlled plasma glucose levels and those with long duration of diabetes. Recently, also, the relationship between diabetic retinopathy and lipids has emerged as an issue of interest. In this study, we evaluated how much $\mathrm{Lp}(\mathrm{a})$ is involved in retinopathy as an independent factor by multiple regression analysis.

\section{Subjects ANd Methods}

One hundred fifty-eight patients ( 83 male and 75 female) with non-insulindependent diabetes mellitus (NIDDM) diagnosed by the World Health Organization (WHO) criteria and 46 non-diabetic age- and sex-matched control subjects

TABLE 1. Basic statistical data in non-insulin dependent diabetic patients

\begin{tabular}{|c|c|c|c|}
\hline & $\underset{(n=158)}{\text { All }}$ & $\begin{array}{c}\text { Male } \\
(n=83)\end{array}$ & $\begin{array}{l}\text { Female } \\
(n=75)\end{array}$ \\
\hline $\mathrm{Lp}(\mathrm{a})(\mathrm{mg} / 100 \mathrm{ml})$ & $23.6 \pm 15.7$ & $21.3 \pm 12.3$ & $26.2 \pm 18.4$ \\
\hline $\operatorname{Sex}(M=1, F=2)$ & $1.48 \pm 0.51$ & & \\
\hline Age (years) & $58.6 \pm 11.4$ & $56.8 \pm 12.4$ & $60.5 \pm 10.1$ \\
\hline BMI $\left(\mathrm{kg} / \mathrm{m}^{2}\right)$ & $22.7 \pm 4.3$ & $22.2 \pm 3.7$ & $23.3 \pm 4.8$ \\
\hline Duration (years) & $9.1 \pm 7.2$ & $9.1 \pm 7.3$ & $9.1 \pm 7.1$ \\
\hline IHD $($ negative $=0$, positive $=1$ ) & $0.17 \pm 0.37$ & $0.16 \pm 0.37$ & $0.17 \pm 0.38$ \\
\hline $\mathrm{FPG}(\mathrm{mg} / 100 \mathrm{ml})$ & $174.6 \pm 60.9$ & $169.6 \pm 54.2$ & $180.2 \pm 67.4$ \\
\hline HbAlc $(\%)$ & $7.74 \pm 2.32$ & $7.54 \pm 2.23$ & $7.97 \pm 2.41$ \\
\hline $\mathrm{TC}(\mathrm{mg} / 100 \mathrm{ml})$ & $210.9 \pm 44.1$ & $202.7 \pm 42.1$ & $219.9 \pm 44.7^{*}$ \\
\hline $\mathrm{TG}(\mathrm{mg} / 100 \mathrm{ml})$ & $125.9 \pm 91.1$ & $130.6 \pm 92.4$ & $120.7 \pm 89.9$ \\
\hline $\mathrm{HDL}-\mathrm{C}(\mathrm{mg} / 100 \mathrm{ml})$ & $52.9 \pm 16.8$ & $49.6 \pm 17.2$ & $56.7 \pm 15.7^{*}$ \\
\hline $\begin{array}{l}\text { Treatment } \\
(\text { diet }=1, \mathrm{OHA}=2, \text { insulin }=3)\end{array}$ & $1.77 \pm 0.84$ & $1.71 \pm 0.86$ & $1.84 \pm 0.82$ \\
\hline $\begin{array}{l}\mathrm{DN}(\text { nonDN }=1, \text { incipient } \mathrm{DN}=2, \\
\text { clinical } \mathrm{DN}=3)\end{array}$ & $1.33 \pm 1.23$ & $1.41 \pm 1.24$ & $1.24 \pm 1.21$ \\
\hline $\mathrm{DR}(\mathrm{nonDR}=1, \mathrm{SDR}=2, \mathrm{PDR}=3)$ & $1.66 \pm 0.67$ & $1.67 \pm 0.69$ & $1.64 \pm 0.63$ \\
\hline
\end{tabular}

Values are mean \pm s.D. ${ }^{*} p<0.05$ vs. male.

$\mathrm{Lp}(\mathrm{a})$, lipoprotein (a); BMI, body mass index; IHD, ischemic heart disease; FPG, fasting plasma glucose; HbAlc, hemoglobin Alc; TC, total cholesterol; TG, triglyceride; HDL-C, high-density lipoprotein cholesterol; OHA, oral hypoglycemic agents; $\mathrm{DN}$, diabetic nephropathy; incipient DN, urinary albumin $30-300 \mathrm{mg}$ /day or $20-200$ $\mathrm{mg} / \mathrm{g}$ creatinine; clinical DN, urinary albumin $300-\mathrm{mg} /$ day or $200-\mathrm{mg} / \mathrm{g}$ creatinine; $\mathrm{DR}$, diabetic retinopathy; SDR, simple DR; PDR, proliferative DR. 
were studied. Age, body mass index (BMI) and the other characteristics of the patients were shown in Table 1. Patients with renal insufficiency with a serum creatinine level of $2.0 \mathrm{mg} / 100 \mathrm{ml}$ or higher and those with nephrotic syndrome were excluded. Patients with severe liver disorders and those who were taking nicotinic acid preparations (niceritrol and tocopheryl nicotinate), which are reported to reduce the serum $\operatorname{Lp}(\mathrm{a})$ concentration, were also excluded.

Multiple regression analysis was carried out with the severity of diabetic retinopathy as the dependent variable and 13 independent variables, namely the $\mathrm{Lp}$ (a) concentration, sex, age, BMI, duration of diabetes, ischemic heart disease (IHD), fasting plasma glucose (FPG), glycosylated hemoglobin Alc (HbAlc), total cholesterol (TC), triglyceride (TG), high-density lipoprotein cholesterol (HDL-C), anti-diabetic treatments, and diabetic nephropathy.

Diabetic retinopathy was diagnosed using ophthalmoscopy with fluorescence angiography by ophthalmologists. The subjects were classified into three groups; 71 patients without retinopathy, 70 with simple retinopathy, and 17 with proliferative retinopathy.

Nephropathy was considered to be absent when the excretion of albumin in 24-hr pooled urine was less than $30 \mathrm{mg} /$ day or the urinary albumin/urinary creatinine ratio in randomly sampled urine was less than $20 \mathrm{mg} / \mathrm{g}$ creatinine, to be incipient when the former was $30 \mathrm{mg} /$ day or above and less than $300 \mathrm{mg} /$ day or the latter was $20 \mathrm{mg} / \mathrm{g}$ creatinine or above and less than $200 \mathrm{mg} / \mathrm{g}$ creatinine, and to be clinical when the former was $300 \mathrm{mg} /$ day or above or the latter was $200 \mathrm{mg} /$ $\mathrm{g}$ creatinine or above. The subjects were divided according to the urinary albumin level into three groups; 69 without nephropathy, 57 with incipient nephropathy, and 32 with clinical nephropathy.

IHD was considered to be positive when the patient showed a past history of myocardial infarction, anginal attacks, or ischemic ST-T changes in resting ECG and to be negative when the patient had none of them. The subjects were divided into two groups; 132 negative and 26 positive patients.

Concerning anti-diabetic treatments, the subjects were divided according to the treatments; 78 who were undergoing dietary therapy alone, 38 who were receiving oral hypoglycemic agents $(\mathrm{OHA})$, and 42 who were receiving insulin injections.

FPG was measured by the glucose oxidase method, TC and TG by the enzymatic method, HDL-C by the precipitation method, and HbAlc by HPLC. The serum $\mathrm{Lp}$ (a) concentration was assayed by ELISA (Abe et al. 1988) using a TintElize ${ }^{\mathrm{TM}} \mathrm{Lp}(\mathrm{a})$ (Biopool Co., Umeá, Sweden).

Data are expressed as means \pm S. D. Statistical analysis for the difference of mean values was compared between each group using non-parametrical tests (Wlicoxon's sign rank sum test for two groups and Kruskal-Wallis test for three or more). Correlation between the diabetic retinopathy and 12 items in NIDDM were calculated using Spearmann's rank correlation. The relationship among 
multiple parameters were determined by Multiple regression analysis. A $p$ value below 0.05 was considered significant.

\section{RESULTS}

The frequency distributions of serum $L p(a)$ level in diabetic patients and in control subjects are shown in Fig. 1. The distribution was skewed to the left in both groups. In most patients, $\mathrm{Lp}$ (a) levels were in the range of $10-20 \mathrm{mg} / 100$ $\mathrm{ml}$. The distribution of patients with $\mathrm{Lp}$ (a) levels above $20 \mathrm{mg} / 100 \mathrm{ml}$ showed a gradual decrease. The percentage of diabetic patients having $\operatorname{Lp}(\mathrm{a})$ levels above $20 \mathrm{mg} / 100 \mathrm{ml}$ was significantly higher than that of control subjects (48.7 vs. $26.1 \%, p<0.001)$.

The serum $\mathrm{Lp}$ (a) level in all diabetic patients was significantly higher than that in control subjects $(23.6 \pm 15.7$ vs. $17.2 \pm 11.6 \mathrm{mg} / 100 \mathrm{ml}, p<0.01)$. The $\mathrm{Lp}$ (a) level in patients with simple retinopathy $(25.0 \pm 14.4 \mathrm{mg} / 100 \mathrm{ml})$ was significantly higher $(p<0.05)$ than that in control subjects, and the level in patients with proliferative retinopathy $(29.4 \pm 16.2 \mathrm{mg} / 100 \mathrm{ml})$ was significantly higher than those in patients without retinopathy $(20.9 \pm 16.4 \mathrm{mg} / 100 \mathrm{ml}, p<$ $0.05)$ and in control subjects $(p<0.05)$.

Table 1 shows the mean values of various parameters separately in all patients, males only, and females only. TC and HDL-C were significantly higher $(p<0.05)$ in females than in males. Table 2 shows simple correlations between diabetic retinopathy and the 13 variables. Significant correlations were observed between diabetic retinopathy and the duration of diabetes, anti-diabetic treatments, and diabetic nephropathy in all the three groups and between diabetic retinopathy and $\operatorname{Lp}(\mathrm{a})$ in males.

Multiple regression analysis was performed using these 13 parameters as independent variables against diabetic retinopathy. Table 3 shows standard partial regression coefficients and multiple correlation coefficients. In males, the

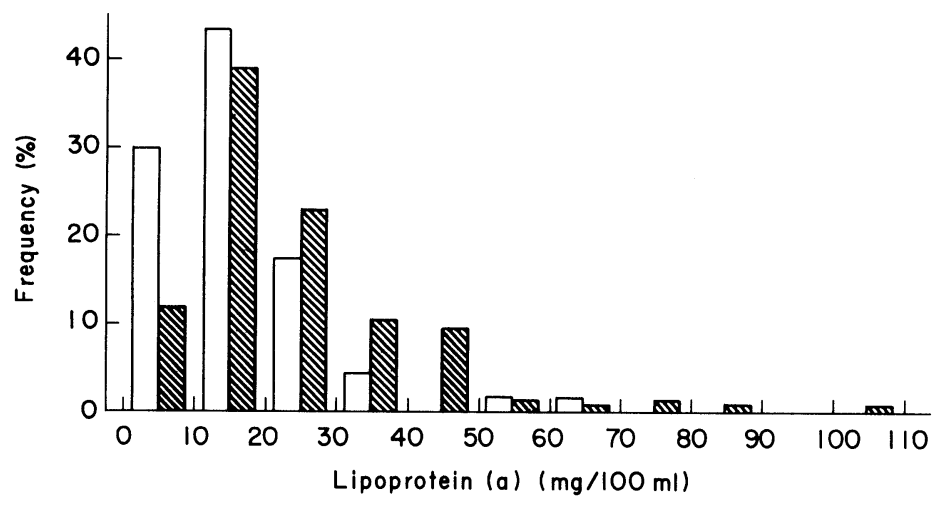

Fig. 1. Frequency distribution of serum lipoprotein(a) in diabetic patients $(\mathrm{n}=$ $154, \mathbb{N})$ and control subjects $(\mathrm{n}=46$, 
TABLE 2. Correlation coefficients between diabetic retinopathy and 13 items in noninsulin dependent diabetic patients

\begin{tabular}{rlccc}
\hline & & $\begin{array}{c}\text { All } \\
(n=158)\end{array}$ & $\begin{array}{c}\text { Male } \\
(n=83)\end{array}$ & $\begin{array}{c}\text { Female } \\
(n=75)\end{array}$ \\
\hline 1 & Lp(a) & $0.177^{*}$ & $0.336^{* *}$ & 0.068 \\
2 & Sex & -0.026 & & \\
3 & Age & 0.042 & 0.099 & -0.033 \\
4 & BMI & -0.014 & 0.096 & -0.115 \\
5 & Duration & $0.329^{* * *}$ & $0.348^{* *}$ & $0.307^{* *}$ \\
6 & IHD & -0.029 & -0.132 & 0.095 \\
7 & FPG & 0.041 & -0.133 & 0.217 \\
8 & HbAlc & -0.029 & -0.121 & 0.081 \\
9 & TC & 0.017 & 0.069 & -0.031 \\
10 & TG & -0.075 & -0.207 & 0.089 \\
11 & HDL-C & 0.034 & 0.005 & 0.089 \\
12 & Treatment & $0.325^{* * *}$ & $0.347^{* *}$ & $0.305^{* *}$ \\
13 & DN & $0.379^{* * *}$ & $0.394^{* * *}$ & $0.291^{*}$ \\
\hline
\end{tabular}

${ }^{*} p<0.05,{ }^{* *} p<0.01,{ }^{* * *} p<0.001$

Abbreviations are described in Table 1.

TABLE 3. Multiple regression analysis of diabetic retinopathy

\begin{tabular}{rllcc}
\hline & & \multicolumn{2}{c}{ Standard partial regression coefficient } \\
\cline { 3 - 5 } & & $\begin{array}{c}\text { All } \\
(n=158)\end{array}$ & $\begin{array}{c}\text { Male } \\
(n=83)\end{array}$ & $\begin{array}{c}\text { Female } \\
(n=75)\end{array}$ \\
\hline 1 & Lp(a) & 0.119 & $0.293^{* *}$ & 0.016 \\
2 & Sex & -0.032 & & \\
3 & Age & -0.143 & -0.211 & -0.206 \\
4 & BMI & -0.042 & 0.019 & -0.168 \\
5 & Duration & $0.234^{* *}$ & 0.184 & $0.261^{*}$ \\
6 & IHD & -0.011 & -0.099 & 0.095 \\
7 & FPG & 0.123 & -0.105 & 0.287 \\
8 & HbAlc & -0.102 & -0.004 & -0.079 \\
9 & TC & 0.039 & 0.181 & -0.164 \\
10 & TG & -0.115 & $-0.322^{* *}$ & 0.177 \\
11 & HDL-C & -0.016 & -0.047 & 0.156 \\
12 & Treatment & $0.222^{* *}$ & $0.242^{*}$ & 0.116 \\
13 & DN & $0.226^{* *}$ & $0.295^{*}$ & 0.211 \\
\hline R & 0.441 & 0.611 & 0.411 \\
\hline
\end{tabular}

${ }^{*} p<0.05,{ }^{* *} p<0.01 . \quad \mathrm{R}$, multiple correlation coefficient. 
standard partial correlation coefficient of $\operatorname{Lp}(a)$ was significant $(0.293, p<0.01)$, and the multiple correlation coefficient was 0.611 . However, the standard partial correlation coefficient of $\mathrm{Lp}(\mathrm{a})$ was not significant in all patients and in females only at 0.119 and 0.016 , respectively, and the multiple correlation coefficient was 0.441 and 0.411 , respectively. The rank of $\mathrm{Lp}(\mathrm{a})$ in contribution to diabetic retinopathy was the third, following TG and diabetic nephropathy and followed by anti-diabetic treatments.

In 132 patients (65 males and 67 females) with serum creatinine level less than $1.0 \mathrm{mg} / 100 \mathrm{ml}$, the standard partial regression coefficient of $\mathrm{Lp}(\mathrm{a})$ was significant $(0.336, p<0.01)$ in males, and was not significant in all patients and in females only.

\section{Discussion}

$\mathrm{Lp}(\mathrm{a})$ is reported to be an independent risk factor for coronary atherosclerosis (Rosengren 1990), but increasing attention is being directed also to its relationship with diabetic microvascular diseases. Especially, a relationship between nephropathy and high Lp(a) levels has been reported by Takegoshi et al. (1990), Winocour et al. (1991), Kapelrud et al. (1991), and Jenkins et al. (1991). There have been a few reports concerning the relationship between diabetic retinopathy and $\operatorname{Lp}(\mathrm{a})$. One shows similar level of $\mathrm{Lp}(\mathrm{a})$ and others show high level in patients with the retinopathy compared with patients without it. Furthermore, it remains unknown if diabetic retinopathy is related to $\operatorname{Lp}(\mathrm{a})$ independent of other risk factors.

Diabetic retinopathy is one of diabetic microvascular complications and is the most common cause of blindness in adults. Various factors are considered to be involved in the pathogenesis of retinopathy, but prolonged hyperglycemia has a great effect of them. Clinically, however, retinopathy is often observed in patients in whom the blood sugar level is considered to be relatively well controlled so that factors other than prolonged hyperglycemia are considered to be involved.

In this study, we evaluated how much $L p(a)$ is involved in retinopathy as an independent factor by multiple regression analysis. In males, $\mathrm{Lp}$ (a) contributed to retinopathy independently of the other 12 factors and ranked third in the importance of contribution, following TG and diabetic nephropathy.

The frequency of microvascular complications is expected to increase with the duration of illness. Similarly, the treatment for diabetes often progresses from dietary therapy to OHA and to insulin injection as the disease is prolonged. To date, there have not been a report of long-term monitoring of the $\mathrm{Lp}$ (a) concentration. The $\operatorname{Lp}(\mathrm{a})$ concentration is considered to be regulated genetically and not to be affected by the sex, age, or diet. All the patients of this study were not taking nicotinic acid preparations which were considered to reduce serum $\mathrm{Lp}$ (a) level. It is suggested that $\mathrm{Lp}(\mathrm{a})$ may be a genetic determinant of the develop- 
ment of diabetic retinopathy. Prospective studies are needed to clarify the relationship between retinopathy and $L p(a)$.

It was previously reported that serum $\mathrm{Lp}$ (a) level was increased in response to the administration of an anabolic steroid (Albers et al. 1984). A recent study has shown that serum $\operatorname{Lp}(\mathrm{a})$ level is reduced by using estrogen in a man with familiar hypercholesterolemia (Hiraga et al. 1992). However, the influence of steroid hormones in the metabolism of $\mathrm{Lp}(\mathrm{a})$ is still controversial. In this study, the involvement of $\mathrm{Lp}(\mathrm{a})$ in retinopathy was not confirmed in females. The involvement of $\mathrm{Lp}(\mathrm{a})$ was also not confirmed in 55 postmenopausal females. There was no difference in the $L p(a)$ concentration or the severity of retinopathy between males and females. Also, the standard partial regression coefficients between retinopathy and various parameters were low in females except for the duration of diabetes. The sex difference observed in the relationship between the $\mathrm{Lp}$ (a) concentration and the severity of retinopathy suggests the involvement of factors other than those evaluated in this study.

In conclusion, $L p(a)$ was suggested to be an independent risk factor for diabetic retinopathy in male patients with NIDDM.

\section{Acknowledgments}

We are most grateful to Prof. Shigeru Takamatsu for his active interest and discussions during the preparation of the manuscript. We are also grateful to Dr. Makoto Tsuboi (Sanwakagaku Co.) for his advice in multiple regression analysis of our data.

\section{References}

1) Abe, A., Maeda, S., Makino, K., Seishima, M., Shimokawa, K., Noma, A. \& Kawade, M. (1988) Enzyme-linked immunosorbent assay of lipoprotein(a) in serum and cord blood. Clin. Chim. Acta, 177, 31-40.

2) Albers, J.J., Taggart, H.M., Applebaum-Bowden, D., Haffner, S., Chestnut, C.H., III \& Hazzard, W.R. (1984) Reduction of lecithin-cholesterol acyltransferase, apolipoprotein D and the $\mathrm{Lp}(\mathrm{a})$ lipoprotein with the anabolic steroid stanozolol. Biochim. Biophys. Acta, 795, 293-296.

3) Arauz, C., Lackner, C. \& Ramirez, L.C. (1990) Lipoprotein(a) levels in diabetic patients and it's correlation with the metabolic control. Diabetes, 39, Suppl. 1, 64A.

4) Berg, K. (1963) A new serum type system in man - The Lp system. Acta Pathol. Microbiol. Scand., 59, 369-382.

5) Fless, G.M., ZumMallen, M.E. \& Scanu, A.M. (1986) Physico-chemical properties of apolipoprotein(a) and lipoprotein(a) derived from the dissociation of human plasma lipoprotein(a). J. Biol. Chem., 261, 8712-8718.

6) Hiraga, N., Harada, K., Kobayashi, T. \& Murase, T. (1992) Reduction of serum lipoprotein(a) using estrogen in a man with familial hypercholesterolemia. J.A.M.A., 267, 2328.

7) Jenkins, A.J., Steele, J.S., Janus, E.D. \& Best, J.D. (1991) Increased plasma apolipoprotein(a) levels in IDDM patients with microalbuminuria. Diabetes, 40, 787790.

8) Kapelrud, H., Bangstad, H.J., Dahl-Jorgensen, K., Berg, K. \& Hanssen, K.F. (1991) Serum $\mathrm{Lp}(\mathrm{a})$ lipoprotein concentrations in insulin dependent diabetic patients with microalbuminuria. $B r . M e d . J ., 303,675-678$. 
9) Kohner, E.M. \& Porta, M. (1990) Diabetic retinopathy. In: The Diabetes Annual. vol. 5. edited by K.G.M.M. Alberti \& L.P. Krall, Elsevier, Amsterdam, pp. 273-300.

10) Maioli, M., Tonolo, G., Pacifico, A., Ciccarese, M., Brizzi, P., Kohner, E.M. \& Porta, M. (1993) Raised serum apolipoprotein(a) in active diabetic retinopathy. Diabetologia, 36, 88-90.

11) Rosengren, A., Wilheimsen, L., Eriksson, E., Risberg, B. \& Wedel, H. (1990) Lipoprotein(a) and coronary heart disease: A prospective case-control study in a general population sample of middle aged men. Br. Med. J., 301, 1248-1251.

12) Takegoshi, T., Haba, T., Hirai, J., Kitoh, C., Suga, T., Yamazaki, Y. \& Mabuchi, H. (1990) Alterations of lipoprotein(a) in patients with diabetic nephropathy. Atherosclerosis, 83, 99-100.

13) Winocour, P.H., Bhatnagar, D., Ishola, M., Arrol, S. \& Durrington, P.N. (1991) Lipoprotein(a) and microvascular disease in type 1 (insulin-dependent) diabetes. Diabetic Med., 8, 922-927. 